\title{
Optimal management of perimenopausal depression
}

\author{
This article was published in the following Dove Press journal: \\ International Journal of Women's Health \\ 8 June 2010 \\ Number of times this article has been viewed
}

\section{Barbara L Parry \\ Department of Psychiatry, University of California, San Diego, USA}

\begin{abstract}
Only recently has the perimenopause become recognized as a time when women are at risk for new onset and recurrence of major depression. Untreated depression at this time not only exacerbates the course of a depressive illness, but also puts women at increased risk for sleep disorders, cardiovascular disease, diabetes, and osteoporosis. Although antidepressant medication is the mainstay of treatment, adjunctive therapy, especially with estrogen replacement, may be indicated in refractory cases, and may speed the onset of antidepressant action. Many, but not all, studies, report that progesterone antagonizes the beneficial effects of estrogen. Although some antidepressants improve vasomotor symptoms, in general they are not as effective as estrogen alone for relieving these symptoms. Estrogen alone, however, does not generally result in remission of major depression in most (but not all) studies, but may provide benefit to some women with less severe symptoms if administered in therapeutic ranges. The selective serotonin reuptake inhibitors (SSRIs) in addition to estrogen are usually more beneficial in improving mood than SSRIs or estrogen treatment alone for major depression, whereas the selective norepinephrine and serotonin reuptake inhibitors do not require the addition of estrogen to exert their antidepressant effects in menopausal depression. In addition to attention to general health, hormonal status, and antidepressant treatment, the optimal management of perimenopausal depression also requires attention to the individual woman's psychosocial and spiritual well being.
\end{abstract}

Keywords: menopause, depression, management

\section{Introduction}

Kraepelin initially described involutional melancholia as a distinct clinical entity characterized by late onset, symptoms of fear, despondency, agitation, and hypochondriacal delusions, which formed the basis of the nomenclature in the second edition of the Diagnostic and Statistical Manual of Mental Disorders (DSM-II). ${ }^{1}$ A subsequent report discounted a syndrome of depression at menopause, ${ }^{2}$ which served as the basis for the removal of involutional melancholia from the DSM-III. ${ }^{3}$ Subsequent findings from the Cross-National Epidemiologic Study indicated an increase in new onset of depressive illness in the perimenopausal years (women aged 45-49). This later work is consistent with a developing database demonstrating an increased risk of major depressive episodes occurring in association with hormonal changes in the perimenopausal years.

The perimenopausal years refer to the time period when women's menstrual cycles become irregular, generally between 45-49 years. According to the World Health Organization and the Stages of Reproductive Aging Workshop (STRAW), ${ }^{4}$ menopause is
University of California, San Diego, 9500

Gilman Dr, La Jolla, CA 92093-0804, USA

Tel + I 6195435592

Fax + I 6195437519

Email bparry@ucsd.edu 
defined as 12 months of amenorrhea following the final menstrual cycle, the mean age of which is 51 years, when levels of follicle stimulating hormone (FSH) exceed $40 \mathrm{mIU} / \mathrm{mL}$. The determination of menopausal status generally is made by clinical history rather than laboratory parameters, however, given the variability of individual hormonal levels.

\section{Increased incidence of major depressive disorder at menopause}

Many methodologic problems, especially of diagnostic and endocrine heterogeneity, characterize studies of menopausal mood disorders. More rigorous studies, which use standardized, interview-based assessments of depression in endocrinedefined phases of the menopausal transition, support an association between major depressive disorder (MDD) and menopause. In one such study from the National Institute of Mental Health (NIMH), Schmidt et $a l^{5}$ conducted a longitudinal evaluation of the relationship between reproductive status and mood in perimenopausal women. The investigators used the structured clinical interview for DSM-IV (SCID) ${ }^{6}$ for assessment of psychiatric diagnoses, and plasma levels of FSH obtained at 3-6 month intervals for an average of five years, to determine pre-, peri-, or postmenopausal status. For the 24 months surrounding women's final menses, the risk for onset of depression was 14 times higher than for a 31-year pre-menopausal time period. Women who developed a major depressive episode (MDE) during the perimenopause were not distinguished from those who remained asymptomatic on the basis of symptom profiles, personal or family history of depression, duration of the perimenopause, vasomotor symptoms, life events, medical illness, use of medication, vitamins, minerals, or exercise. The timing of the depression, occurring in the context of recently elevated FSH levels, suggested that an endocrine mechanism related to the perimenopause (estradiol withdrawal and recent onset of prolonged hypogonadism) was involved in the pathophysiology of perimenopausal depression. Other systematic studies are consistent with these findings. In an eight-year study, Freeman et $\mathrm{al}^{7}$ followed 231 women without depressive histories who were about to enter menopause. Using the Center for Epidemiological Studies of Depression (CES-D) ${ }^{8}$ scale, they found that the probability of a high depression score $(>16)$ was four-fold greater during the menopausal transition than during the premenopausal phase. Entering menopause was linked to more than double the risk of being diagnosed with a depressive disorder and was associated with within-woman increases in FSH and luteinizing hormone $(\mathrm{LH})$, and greater variability of estradiol and FSH.
Cohen et $\mathrm{al}^{9}$ also examined the impact of the menopausal transition on depressive symptoms in 460 women without depressive histories aged between 36 and 45 years. During three years of follow-up, the menopausal group, especially women with hot flashes, was twice as likely to experience significant depressive symptoms as the premenopausal group. Major mood disorders occurred in $9.5 \%$ of premenopausal and $16.6 \%$ of perimenopausal women. These studies all used rigorous, standardized criteria for making psychiatric diagnoses, and their results lend strong support to the hypothesis of increased vulnerability to an MDE occurring at the time of the menopausal transition.

\section{Clinical phenomenology and epidemiology}

Based on studies from menopause clinics (see review ${ }^{10}$ ), the most common symptom for which women seek treatment at menopause is mood change. Almost half of these women are clinically depressed and over a third experience their first episode of depression in the perimenopausal period. Twothirds of women in London and three-quarters of women in San Diego attending a university or community menopause clinic met criteria for recurrent MDD when evaluated by a psychiatric interview. ${ }^{11}$ Peri- compared with pre- or postmenopausal women had a significant increase in depression rating scores. Mood and sleep disturbances were the most common symptoms in about $75 \%$ of women. Depressive episodes also are likely to recur in women with bipolar illness at menopause, ${ }^{12}$ and there is an increased number of suicides in women during this time period (45-64 years). ${ }^{13}$

\section{Sleep}

Systematic studies examining objective measures of sleep in carefully diagnosed patients in relation to endocrine markers of the menopause are limited, and the findings inconsistent. ${ }^{14}$ Perceptions of sleep quality may differ in depressed, compared with healthy menopausal women, and although women may complain of sleep disturbances more than men, they actually have better sleep quality as documented by objective recordings. ${ }^{15}$ Depressed menopausal women may also report increased severity of hot flashes during sleep, but in skin conductance studies of hot flashes, they actually have fewer and shorter hot flashes that disrupt sleep. Moreover, sleep disturbances at menopause are related more to underlying sleep disorders (such as restless leg syndrome or apnea) or anxiety symptoms than to hot flashes. Hot flashes are more likely to disrupt sleep in the first, compared with the second, half of the night because of the suppressive effects of rapid eye 
movement (REM) sleep, which occurs predominantly in the second half of the night, on thermoregulation. ${ }^{16}$ Women with chronic insomnia, however, are at higher risk for developing depression. In subjective reports of sleep, lower estradiol levels have been associated with poorer sleep quality, increased hot flashes, and increased anxiety and depressive symptoms. Estrogen treatment may improve sleep independent of its effect on hot flashes. In the Women's Health Initiative (WHI), increased light exposure was associated with improved sleep and mood in older women. ${ }^{17}$

\section{Past history}

Studies of past psychiatric histories, including illness related to reproductive endocrine change, in women with menopausal depression support a depressive diathesis at menopause. Women who develop psychiatric symptoms in middle age are more likely to evidence psychiatric vulnerability, ie, a previous personal or family psychiatric history. A past history of depressive disorder occurs in over half of the women. In a five-year study of 2,565 women aged 45 to $55,{ }^{18}$ prior depression was the variable most predictive of subsequent depression.

Psychiatric symptoms at menopause are also related to previous depression associated with the reproductive cycle, such as premenstrual syndrome (PMS) or depression during pregnancy or the postpartum period. Stewart and Boydell ${ }^{19}$ found that psychologic distress during menopause was associated with a past history of PMS, depressive disorders treated with antidepressant medication, oral contraceptive-induced dysphoria, postpartum blues and MDD, suggesting an increased sensitivity to reproductive hormones in these psychiatrically vulnerable women. Freeman et $\mathrm{al}^{20}$ found that PMS was a predictor of menopausal symptoms and that women in the menopausal transition were up to three times more likely to report depressive symptoms than premenopausal women. A history of depression was the strongest predictor of these changes. ${ }^{21}$ In interviews of 347 women $35-55$ years of age in the Seattle Midlife Women's Health Study, Woods and Mitchell ${ }^{22}$ found that a history of either premenstrual or postpartum affective symptoms distinguished women with consistently depressed mood.

Evidence supports the contention that the perimenopause increases susceptibility to depression, particularly, but not necessarily, among women with life-long susceptibility to MDD, including those whose MDEs were induced by reproductive endocrine change (eg, during the premenstruum, pregnancy, or postpartum).

\section{Risks of untreated depression}

To determine the optimal treatment for perimenopausal depression, clinicians must weigh the risks of untreated depression and the benefits of treatment. Untreated depression during the perimenopause exacerbates heart disease, diabetes, and osteoporosis. ${ }^{23-26}$ More specifically, with regard to cardiovascular (CV) disease, a higher prevalence of depressive disorders was associated with more severe atherosclerosis; ${ }^{27}$ recurrent depressive, but not anxiety, disorders were associated with a two-fold increase in the risk of carotid atherosclerosis in middle-aged women, however, lifetime history of a single depressive episode was not associated with increased risk of plaque, suggesting that prevention of recurrent depressive episodes may prevent further progression of atherosclerosis; patients with depressive symptoms have lower health benefits (lower functioning) after coronary artery bypass surgery; ${ }^{28}$ symptoms of depression are significantly related to increased risk of $\mathrm{CV}$ events in women suspected of myocardial ischemia, ${ }^{29}$ to death from $\mathrm{CV}$ disease and, based on the findings from the WHI observational study, to all-cause mortality, even after controlling for established CV disease risk factors. ${ }^{30}$ As Eaton reviews, ${ }^{31}$ major depression increases the risk of first heart attack (odds ratio [OR] 3.9), stroke (OR 2.7) and diabetes (OR 2.23). In addition to depression being associated with increased bone loss ${ }^{32-35}$ and fracture, ${ }^{36}$ it is also associated with other menopausal symptoms of urinary incontinence ${ }^{37}$ and hot flashes. ${ }^{38}$

\section{Contributing endocrine mechanisms}

To provide optimal treatment for perimenopausal depression, it is worthwhile to examine the possible contributing endocrine mechanisms. Harlow et $\mathrm{al}^{39}$ found that women with a history of depression were at increased risk for an earlier perimenopausal transition with higher FSH and LH levels and lower estradiol (E2) levels. In a study examining hormonal predictors of depression in women in transition to the menopause, Freeman et $\mathrm{al}^{21}$ found that rapidly increasing FSH levels were associated with a decreased likelihood of depressive symptoms, whereas increasing estradiol levels were associated with more depressive symptoms. In a later study, Freeman et $\mathrm{al}^{7}$ observed that in women without a history of depression who were undergoing the menopausal transition, increased depression ratings on the Center for Epidemiological Studies of Depression scale (CES-D) were associated with increased levels of FSH and LH and increased variability of estradiol, FSH and LH. Other than lower morning dehydroepiandrosterone (DHEA) and its 
sulfated metabolite DHEA-S, Schmidt et $\mathrm{al}^{5,40}$ did not find associations between basal plasma hormone levels (FSH, LH, E2, estrone-E1, total-T or free testosterone-FT, E2/LH ratio, cortisol) in women with first onset of major or minor depression during the perimenopause and matched healthy comparison women. However, women with hot flashes who were older, regardless of the presence of depression, had significantly higher plasma levels of FT, LH, and FSH, and lower E2/LH ratios. ${ }^{40}$ Depressed mood was also not related to hormonal measures of urinary estrone glucuronide, FSH, or testosterone in the Seattle Midlife Women's Health study. ${ }^{41}$ Increased FSH levels and older age can be associated with a poor response to antidepressant treatment in post- versus premenopausal women. ${ }^{42}$ Earlier age at menopause in women with lower educational levels increased their risk of depression, but long-term oral contraceptive use ( $>10$ years) was protective against depression. ${ }^{43}$ Earlier bilateral oophorectomy before the onset of menopause is associated with an increased risk of depressive symptoms. ${ }^{44}$

It may be the alteration of sleep-endocrine relationships that is associated with major depression during the menopause transition. Antonijevic et $\mathrm{al}^{45}$ found increased nocturnal cortisol and alterations in FSH secretion in relation to slow wave sleep in postmenopausal depressed women compared with postmenopausal controls. It also may be that fluctuating, rather than absolute, hormonal levels are associated with depressive symptoms, emphasizing the need for prospective studies. For example, Ryan et $\mathrm{al}^{46}$ in their prospective study of the association between endogenous hormones and depressive symptoms in postmenopausal women found no significant associations between depressive symptoms and absolute levels of sex hormone-binding globulin, testosterone, free androgen index, estradiol, free estradiol, or FSH, but did find that women with a decline in total serum estradiol or, to a lesser extent, large increases in FSH over a two-year period had up to a three-fold increased risk of depressive symptoms. In Freeman's 10-year follow-up study, ${ }^{38}$ withinwoman increases in FSH were associated with the onset of depressed mood, which preceded the development of hot flashes, associated with increased FSH levels, decreased inhibin levels, and variability of estradiol levels. A decrease in FSH was correlated with improved scores in verbal memory in perimenopausal women who responded to estrogen augmentation of antidepressant medication. ${ }^{47}$ In postmenopausal depression, improved antidepressant response to SSRIs was inversely correlated with basal levels of $\mathrm{LH} .{ }^{48}$ The effects may be mediated by altered neurotransmitter, neuroendocrine, circadian rhythm, or EEG alpha/beta function. ${ }^{49,50}$
Thus, no specific absolute levels of hormonal profiles that would guide treatment recommendations consistently characterize women at risk for developing perimenopausal depression. Rather, it appears to be the fluctuating levels of hormones during the menopausal transition, and perhaps their effects on other endocrine, neurotransmitter, or circadian systems, that contribute to women's vulnerability for the development of depressive symptoms during the perimenopause.

\section{Treatment}

The studies examining the effects of hormone replacement on mood in menopausal depressed patients vary depending on the diagnosis (eg, MDD), their menopausal status (including the presence of hot flashes), the dose and preparation of estrogen and progesterone replacement, and the duration of treatment (see review ${ }^{51}$ ).

In initial studies ${ }^{52}$ not confined to menopausal women, $25 \mu \mathrm{g}$ of ethinyl estradiol added to imipramine was superior to $50 \mu \mathrm{g}$ of ethinyl estradiol plus imipramine or imipramine alone in 30 women with primary depression. The higher dosage of estrogen, although associated with less insomnia, was also associated with significant side effects (lethargy, hypotension, tremor, depersonalization). These findings suggest there may be a therapeutic window for estrogen treatment; if endogenous levels are already high, additional estrogen supplementation may lead to toxic reactions.

In a six-week nonrandomized trial ${ }^{53}$ in primarily postmenopausal women ( $>60$ years) with unipolar depression, 72 women who received fluoxetine $(20 \mathrm{mg} /$ day $)$ and estrogen replacement therapy (ERT, primarily Premarin ${ }^{\circledR}$ ) had a greater improvement in depression ratings than 286 women on ERT alone ( $40 \%$ versus $17 \%$, respectively). Fluoxetinetreated patients not on ERT did not show benefit greater than placebo. Thus, estrogen enhanced the efficacy of fluoxetine treatment. Ping et $\mathrm{al}^{54}$ also found that hormone replacement therapy (HRT) with $0.625 \mathrm{mg}$ of conjugated estrogen and $5 \mathrm{mg}$ of progesterone combined with $20 \mathrm{mg}$ fluoxetine for two months was more effective in reducing symptoms than HRT alone in 123 women with menopausal depression. In a study of sertraline $(50-150 \mathrm{mg}),{ }^{55}$ women over 60 years receiving ERT (without progesterone) had greater global improvement, better quality of life, less anxiety, and modest improvements in cognitive functioning than women receiving sertraline but not ERT.

In contrast, in our laboratory, we found that although oral (1-2 mg Estrace $\left.{ }^{\circledR}\right)$ or transdermal (0.1-0.2 mg Estraderm ${ }^{\circledR}$ ) 17-beta estradiol enhanced the antidepressant effects of 
fluoxetine (10-40 mg) in an eight-week pilot study of women with peri- or postmenopausal MDD, ${ }^{56}$ in a follow-up randomized clinical trial, the combination of antidepressant (AD) plus estrogen was not superior to $\mathrm{AD}$ alone; in fact, patients receiving $\mathrm{AD}$ plus estrogen showed smaller (nonsignificant) reductions in interview-based depression ratings than those patients receiving $\mathrm{AD}$ alone, ${ }^{51}$ a finding supported by other studies. ${ }^{57}$ Estrogen treatment alone did not significantly reduce symptoms of MDD. Estrogen treatment, however, may accelerate the antidepressant response as shown by Rasgon et $\mathrm{al}^{58}$ with respect to sertraline.

In an open-label pilot study, Freeman et $\mathrm{al}^{59}$ found that the SSRI escitalopram alone for eight weeks significantly improved psychologic, vasomotor, and somatic symptoms. Escitalopram was more efficacious for the treatment of depression than ethinyl estradiol and norethindrone acetate in another study. ${ }^{60}$ Soares et $\mathrm{al}^{61}$ found that in peri- and postmenopausal women with depressive disorders who failed to show remission of depression after four weeks of estrogen therapy, derived benefit from adjunctive treatment for eight weeks with 20-60 mg of citalopram.

In refractory depressed patients, however, estrogen may enhance the efficacy of antidepressant medication. ${ }^{62,63}$ In small studies ${ }^{64,65}$ in which the investigators examined the effect of gradually increasing doses of Premarin or placebo for a month in three premenopausal and eight postmenopausal women with refractory depression, although there was no overall improvement in depression scores with estrogen or placebo, one bipolar patient whose depression had been treatment-resistant for two years, developed mania that began nine days after estrogen treatment. Another patient showed striking improvement after one week of estrogen treatment and was no longer depressed after two weeks, a remission that lasted three months. Thus, occasionally patients do appear to have therapeutic responses to estrogen. In women with treatment-resistant MDD, estrogen supplementation in replacement dosages may have important additive effects to $\mathrm{AD}$ medication, to which menopausal women may otherwise be refractory. Depending on the dosage in relation to progesterone, estrogen also may induce ${ }^{66}$ or stabilize ${ }^{12,67}$ rapid mood cycling in some patients.

In chronic depression, some studies suggested that in menopausal women not on estrogen replacement therapy, efficacy and tolerability were better with tricyclic antidepressant (TCA) medication. To achieve the same degree of efficacy and tolerability with the SSRIs in menopausal depressed women, estrogen replacement needed to be added, presumably to downregulate postsynaptic serotonin receptors (findings based on the animal literature). Additional work, however, supported this differential effect of TCA versus SSRI medication in pre-, but not postmenopausal women. In a further analysis of women over 50 years, although hormone replacement therapy (HRT) enhanced the effect of SSRIs and placebo response, venlafaxine, perhaps because of its dual inhibition of serotonin and norepinephrine receptors, did not differentially affect outcome as a function of the addition of HRT (see review ${ }^{68}$ ), as did mirtazapine in an open trial. ${ }^{69}$ Venlafaxine alone may improve depressive and vasomotor symptoms in women with perimenopausal depression. ${ }^{70}$ Methyltestosterone further augmented the effects of venlafaxine, but was associated with a high dropout rate. ${ }^{71}$ In an open trial of the serotonin-norepinephrine reuptake inhibitor duloxetine, Joffe et $\mathrm{al}^{72}$ found that $60-120 \mathrm{mg}$ reduced symptoms for depression, vasomotor symptoms, sleep, anxiety and pain after eight weeks of treatment.

Other studies suggest that estrogen treatment alone or combined with progestins may reduce depressive symptoms in MDD. ${ }^{63,73-77}$ Klaiber et $\mathrm{al}^{73}$ found that three months of treatment with oral conjugated estrogen 5-25 mg compared with placebo significantly reduced Hamilton ratings of depression for severe persistent depressions in pre- and postmenopausal inpatient women unresponsive to other medications which had been withdrawn for 2-3 weeks, psychotherapy, or electroconvulsive therapy. Treatment, however, resulted in improvement, but not in remission, of symptoms and was not uniform within the group, with women having less chronic illness responding more favorably. A shorter length of illness, but not menopausal status or age, was significantly related to the amount of improvement. The depressed women had elevated levels of monoamine oxidase (MAO) activity, which were reduced with estrogen therapy, but not placebo. The magnitude of improvement did not correlate with MAO levels, however. In a study ${ }^{78}$ of postmenopausal hysterectomized women, those who received conjugated equine estrogens $0.625 \mathrm{mg} /$ day for six months had a significant decrease in depressive mood symptoms as measured by the Hamilton Rating Scale compared with women who received no treatment. In a randomized, controlled trial of eight weeks' treatment with $1 \mathrm{mg}$ /day estradiol patch or placebo, Morrison et $\mathrm{al}^{79}$ found no clinically significant antidepressant effect of estradiol on mild to moderate depression in postmenopausal women. Although no significant increase in depressive symptoms was found with use of medroxyprogesterone $10 \mathrm{mg} /$ day for two weeks, positive affect decreased slightly when combined with estradiol. However, Cagnacci et $\mathrm{al}^{74}$ found that estrogens plus progestins reduced depression and anxiety in climacteric women and that progestins did not 
counteract the beneficial effects of estrogen. In contrast, an earlier cross-sectional study by Palinkas and Barrett-Connor ${ }^{80}$ in women 50 years and older living in California found that women using noncontraceptive estrogen had significantly higher Beck Depression Ratings (score $>13$ ) than untreated women of the same age. After 60 years, depressive symptoms decreased. The authors postulated that more symptomatic women sought treatment.

Overall, in the studies that demonstrated efficacy, 17-beta estradiol, the most active form of estrogen to cross the bloodbrain barrier, was used for at least four weeks. Soares et $\mathrm{al}^{76}$ found that the transdermal patch of $100 \mu \mathrm{g}$ of $17-\beta$-estradiol for 12 weeks was efficacious compared with placebo in women with perimenopausal depressive disorders, and that the antidepressant effects, but not necessarily the benefit on somatic symptoms, was maintained four weeks after withdrawal. Estrogen levels, however, did not correlate with clinical response. Some depressed women had a satisfactory response, despite low levels of estrogen, raising the question of whether estrogen deficiency is really necessary to elicit a therapeutic response. ${ }^{81}$ In a small open-label study, Cohen et $\mathrm{al}^{77}$ found that a four-week course of transdermal estrogen $(100 \mu \mathrm{g} /$ day $)$ benefited both peri- and postmenopausal women. In the studies that used progesterone replacement in addition to estrogen, the progesterone tended to decrease the beneficial effects of estrogen, and in some but not all patients, exacerbated depressive symptoms, especially in those women who had had previous episodes of depression or who developed negative affect from progestin-containing contraceptives.

In non-depressed clinical samples, investigators in $\mathrm{WHI}^{82}$ failed to find a significant effect of estrogen plus progestin on depressive symptom scores after three years. In the Heart and Estrogen/Progestin Replacement Study (HERS), ${ }^{83}$ only women with hot flashes who were assigned to hormone therapy benefited by having better mental health and fewer depressive symptoms. Women without hot flashes assigned to hormone therapy had greater declines in physical functions, energy, and fatigue. In a study of 48 nondepressed women aged 47-57 years, ${ }^{84}$ estrogen treatment (Premarin) enhanced mood, but women given progesterone (Provera ${ }^{\circledR}$ ) showed more negative affect, unless counteracted by higher dosages of estrogen. In nonclinically depressed women who had previously undergone hysterectomy and bilateral oophorectomy, three months of treatment with ethinyl estradiol versus placebo improved depression, anxiety, irritability, and insomnia as assessed by the Hamilton Depression Rating Scale. Treatment with a progestin showed less favorable changes, and the effects were diminished by three months. ${ }^{85}$
For hot flashes, randomized controlled trials of SSRIs, selective norepinephrine reuptake inhibitors (SNRIs), gabapentin and clonidine did provide evidence of efficacy, although the effect was less than that with estrogen therapy (see review $^{86}$ ). Venlafaxine and paroxetine have been studied more extensively than any of the other antidepressants and are more consistent in effectively reducing the frequency and severity of hot flashes. Desvenlafaxine, sertraline, fluoxetine, and citalopram should be considered second- or third-line options. Duloxetine, escitalopram, fluvoxamine, and mirtazapine should be reserved as last-line therapy for hot flashes. ${ }^{87}$ Schmidt et $\mathrm{al}^{75}$ using $0.05 \mathrm{mg} /$ day of the $17 \beta$-estradiol patch for three weeks reduced depressive symptoms in perimenopausal women, irrespective of the presence of hot flashes or the duration of treatment. Treatment of hot flashes with hormone therapy is cost-effective in the US. ${ }^{88}$

Regarding the risks of hormonal therapies, although the WHI initially reported an increased incidence of breast cancer or cardiovascular disease in 4-5/10,000 women over five years, ${ }^{89}$ the majority of the women in this study were older (60-79 years) with higher body mass indices. ${ }^{90}$ More recent evidence suggests that use of HRT within 10 years of the onset of menopause (between 50-59 years) is associated with reduced risk of cardiovascular disease. ${ }^{91}$ According to the North American Menopause Society, it is reasonable to use hormonal therapies to treat menopausal symptoms in the absence of related risk factors such as cardiovascular disease or breast cancer, repeatedly presenting the option of stopping or reducing the dose..$^{92}$ The decision to use HRT should be done in consultation with the individual woman's physician, weighing her particular risks and benefits.

Regarding alternative treatments, St John's wort and black cohosh appear to be the most useful in alleviating mood and anxiety changes (not disorders) during menopause. ${ }^{93}$

\section{Conclusion}

Perimenopausal women in particular are at risk for new onset and recurrence of MDEs. Women with previous histories of PMS or postpartum depression are at increased risk. The symptoms may present with features of melancholia, agitation, somatic symptoms, or sleep disturbances. The increase in MDEs occurring at this time has been found to be linked to hormonal changes of the menopausal transition, namely increased FSH levels, rather than to social or environmental triggers, although changes in valued lifestyle factors associated with, for example, motherhood, family, fertility, or physical rigor and attractiveness, may precipitate depressive mood changes in predisposed or vulnerable women. Women 
who worry about others are at increased risk for developing clinical depression. Other women may value the new-found independence that these lifestyle changes incur.

Untreated depression may exacerbate heart disease, diabetes, and osteoporosis, as well as contributing to an increased risk for suicide and to a more debilitating course of the depression that is more refractory to intervention.

Estrogen treatment alone may reduce hot flashes and improve sleep, but has not been shown consistently to be efficacious as monotherapy in MDD. In some women refractory to particularly SSRI AD medication, addition of estrogen may enhance efficacy, reduce response time, and obviate the need for increasing the $\mathrm{AD}$ dose with its attendant side effects. If a woman cannot tolerate estrogen replacement, then antidepressant medication other than an SSRI (eg, a TCA such as nortriptyline or desipramine; or an SNRI or dual-receptor reuptake inhibitor, eg, mirtazapine, venlafaxine, or duloxetine) should be tried. For vasomotor symptoms in women who cannot tolerate estrogen therapy, paroxetine or venlafaxine are the antidepressants which have the most evidence for efficacy and tolerability. Progesterone may increase depressive symptoms in women with a previous history of depression. Estrogen or progesterone hormone replacement should be given in consultation with a gynecologist or primary care physician who can monitor the development of any untoward side effects on the uterus, breast, or cardiovascular system. Many women may opt to have annual endometrial biopsies as an outpatient procedure.

The North American Menopause Society consensus statement indicates that it is reasonable to use HRT in symptomatic women in the perimenopause and, as recent evidence suggests, up to 10 years after menopause, given that the benefits may outweigh the risks. The most active form of estrogen, 17-beta estradiol, is the most likely to cross the blood-brain barrier and exerts potential beneficial effects on mood, sleep, cognitive function, and vasomotor symptoms.

\section{Acknowledgments}

This work was supported in part by NIH grant R01 MH59919 and NIH Clinical Research Center (CRC) grant M01 RR00827.

\section{Disclosure}

The author reports no conflicts of interest in this work.

\section{References}

1. American Psychiatric Association. DSM-II: Diagnostic and Statistical Manual of Mental Disorders. Washington, DC.: American Psychiatric Association; 1968

2. Weissman MM. The myth of involutional melancholia. JAMA. 1979;242(8):742-744.
3. American Psychiatric Association. DSM-III: Diagnostic and Statistical Manual of Mental Disorders. 3rd ed. Washington, DC: American Psychiatric Association; 1980.

4. Soules MR, Sherman S, Parrott E, et al. Stages of Reproductive Aging Workshop (STRAW). J Womens Health Gend Based Med. 2001;10(9):843-848.

5. Schmidt PJ, Haq N, Rubinow DR. A longitudinal evaluation of the relationship between reproductive status and mood in perimenopausal women. Am J Psychiatry. 2004;161(12):2238-2244.

6. First MB, Gibbon M, Spitzer RL, Williams JBW. Structured Clinical Interview for DSM-IV Axis I Disorders - Research Version. New York, NY: Biometrics Research Department, New York State Psychiatric Institute; 1995.

7. Freeman EW, Sammel MD, Lin H, Nelson DB. Associations of hormones and menopausal status with depressed mood in women with no history of depression. Arch Gen Psychiatry. 2006;63(4):375-382.

8. Roberts RE, Vernon SW. The Center for Epidemiologic Studies Depression Scale: Its use in a community sample. Am J Psychiatry. 1983;140(1):41-46.

9. Cohen LS, Soares CN, Vitonis AF, Otto MW, Harlow BL. Risk for new onset of depression during the menopausal transition: The Harvard study of moods and cycles. Arch Gen Psychiatry. 2006;63(4):385-390.

10. Ayubi-Moak I, Parry BL. Psychiatric aspects of menopause. In: Kornstein SG, Clayton AH, editors. Women's Mental Health. A Comprehensive Textbook. 1st ed. New York, NY: Guildford Press; 2002:132-143.

11. Tam LW, Stucky V, Hanson RE, Parry BL. Prevalence of depression in menopause: A pilot study. Arch Women Ment Health 1999;2(4):175-181.

12. Khan AY, Ludvigson LR, Stewart M, Gorman JM. Menopause manifesting as bipolar symptoms. J Psychiatr Pract. 2007;13(5):339-342.

13. Allgulander C. Suicide and mortality patterns in anxiety neurosis and depressive neurosis. Arch Gen Psychiatry. 1994;51(9):708-712.

14. Parry BL, Martinez LF, Maurer EL, Lopez AM, Sorenson DL, Meliska CJ. Sleep, rhythms and women's mood. Part II: Menopause. Sleep Med Rev. 2006;10(3):197-208.

15. Van den Berg JF, Miedema HM, Tulen JH, Hofman A, Neven AK, Tiemeier H. Sex differences in subjective and actigraphic sleep measures: A population-based study of elderly persons. Sleep. 2009;32(10): 1367-1375.

16. Parry BL. Sleep disturbances are related to sleep disorders and anxiety symptoms. Menopause. 2007;4(5):812-814.

17. Grandner MA, Kripke DF, Langer RD. Light exposure is related to social and emotional functioning and to quality of life in older women. Psychiatry Res. 2006;143(1):35-42.

18. Avis NE, Brambilla D, McKinlay SM, Vass K. A longitudinal analysis of the association between menopause and depression. Results from the Massachusetts Women's Health Study. Ann Epidemiol. 1994;4(3):214-220.

19. Stewart DE, Boydell KM. Psychologic distress during menopause: Associations across the reproductive life cycle. Int J Psychiatry Med. 1993;23(2):157-162.

20. Freeman EW, Sammel MD, Rinaudo PJ, Sheng L. Premenstrual syndrome as a predictor of menopausal symptoms. Obstet Gynecol. 2004;103(5 Pt 1):960-966.

21. Freeman EW, Sammel MD, Liu L, Gracia CR, Nelson DB, Hollander L. Hormones and menopausal status as predictors of depression in women in transition to menopause. Arch Gen Psychiatry. 2004;61(1):62-70.

22. Woods NF, Mitchell ES. Patterns of depressed mood in midlife women: Observations from the Seattle Midlife Women's Health Study. Res Nurs Health. 1996;19(2):111-123.

23. Carney RM, Freedland KE. Treatment-resistant depression and mortality after acute coronary syndrome. Am J Psychiatry. 2009;166(4):410-417.

24. Rivelli S, Jiang W. Depression and ischemic heart disease: What have we learned from clinical trials? Curr Opin Cardiol. 2007;22(4):286-291.

25. Carnethon MR, Biggs ML, Barzilay JI, et al. Longitudinal association between depressive symptoms and incident type 2 diabetes mellitus in older adults: The cardiovascular health study. Arch Intern Med. 2007;167(8):802-807. 
26. Diem SJ, Blackwell TL, Stone KL, et al. Depressive symptoms and rates of bone loss at the hip in older women. J Am Geriatr Soc. 2007;55(6):824-831.

27. Tiemeier H, van Dijck W, Hofman A, Witteman JC, Stijnen T, Breteler MM. Relationship between atherosclerosis and late-life depression: The Rotterdam Study. Arch Gen Psychiatry. 2004;61(4):369-376.

28. Mallik S, Krumholz HM, Lin ZQ, et al. Patients with depressive symptoms have lower health status benefits after coronary artery bypass surgery. Circulation. 2005;111(3):271-277.

29. Rutledge T, Reis SE, Olson MB, et al. Depression symptom severity and reported treatment history in the prediction of cardiac risk in women with suspected myocardial ischemia: The NHLBI-sponsored WISE study. Arch Gen Psychiatry. 2006;63(8):874-880.

30. Wassertheil-Smoller S, Shumaker S, Ockene J, et al. Depression and cardiovascular sequelae in postmenopausal women. The Women's Health Initiative (WHI). Arch Intern Med. 2004;164(3):289-298.

31. Eaton WW. Medical and Psychiatric Comorbidity Over the Course of Life. Washington, DC: American Psychiatric Publishing; 2006.

32. Michelson D, Stratakis C, Hill L, et al. Bone mineral density in women with depression. $N$ Engl J Med. 1996;335(16):1176-1181.

33. Schweiger U, Weber B, Deuschle M, Heuser I. Lumbar bone mineral density in patients with major depression: Evidence of increased bone loss at follow-up. Am J Psychiatry. 2000;157(1):118-120.

34. Jacka FN, Pasco JA, Henry MJ, et al. Depression and bone mineral density in a community sample of perimenopausal women: Geelong Osteoporosis Study. Menopause. 2005;12(1):88-91.

35. Altindag O, Altindag A, Asoglu M, Gunes M, Soran N, Deveci Z. Relation of cortisol levels and bone mineral density among premenopausal women with major depression. Int J Clin Pract. 2007;61(3):416-420.

36. Silverman SL, Shen W, Minshall ME, Xie S, Moses KH. Prevalence of depressive symptoms in postmenopausal women with low bone mineral density and/or prevalent vertebral fracture: Results from the Multiple Outcomes of Raloxifene Evaluation (MORE) study. J Rheumatol. 2007;34(1):140-144.

37. Moghaddas F, Lidfeldt J, Nerbrand C, Jernstrom H, Samsioe G. Prevalence of urinary incontinence in relation to self-reported depression, intake of serotonergic antidepressants, and hormone therapy in middle-aged women: A report from the Women's Health in the Lund Area study. Menopause. 2005;12(3):318-324.

38. Freeman EW, Sammel MD, Lin H. Temporal associations of hot flashes and depression in the transition to menopause. Menopause. 2009;16(4):728-734.

39. Harlow BL, Wise LA, Otto MW, Soares CN, Cohen LS. Depression and its influence on reproductive endocrine and menstrual cycle markers associated with perimenopause: the Harvard Study of Moods and Cycles. Arch Gen Psychiatry. 2003;60(1):29-36.

40. Schmidt PJ, Murphy JH, Haq N, Danaceau MA, St Clair L. Basal plasma hormone levels in depressed perimenopausal women. Psychoneuroendocrinology. 2002;27(8):907-920.

41. Woods NF, Smith-DiJulio K, Percival DB, Tao EY, Mariella A, Mitchell S. Depressed mood during the menopausal transition and early postmenopause: Observations from the Seattle Midlife Women's Health Study. Menopause. 2008;15(2):223-232.

42. Pae CU, Mandelli L, Kim TS, et al. Effectiveness of antidepressant treatments in pre-menopausal versus post-menopausal women: A pilot study on differential effects of sex hormones on antidepressant effects. Biomed Pharmacother. 2009;63(3):228-235.

43. Ryan J, Carriere I, Scali J, Ritchie K, Ancelin ML. Lifetime hormonal factors may predict late-life depression in women. Int Psychogeriatr. 2008;20(6):1203-1218.

44. Rocca WA, Grossardt BR, Geda YE, et al. Long-term risk of depressive and anxiety symptoms after early bilateral oophorectomy. Menopause. 2008;15(6):1050-1059.

45. Antonijevic IA, Murck H, Frieboes RM, Uhr M, Steiger A. On the role of menopause for sleep-endocrine alterations associated with major depression. Psychoneuroendocrinology. 2003;28(3):401-418.
46. Ryan J, Burger HG, Szoeke C, et al. A prospective study of the association between endogenous hormones and depressive symptoms in postmenopausal women. Menopause. 2009;16(3):509-517.

47. Morgan ML, Cook IA, Rapkin AJ, Leuchter AF. Estrogen augmentation of antidepressants in perimenopausal depression: A pilot study. J Clin Psychiatry. 2005;66(6):774-780.

48. Zanardi R, Rossini D, Magri L, Malaguti A, Colombo C, Smeraldi E. Response to SSRIs and role of the hormonal therapy in post-menopausal depression. Eur Neuropsychopharmacol. 2007;17(6-7):400-405.

49. Saletu B, Brandstatter N, Metka M, et al. Double-blind, placebocontrolled, hormonal, syndromal and EEG mapping studies with transdermal oestradiol therapy in menopausal depression. Psychopharmacology (Berl). 1995;122(4):321-329.

50. Stahl SM. Effects of estrogen on the central nervous system. J Clin Psychiatry. 2001;62(5):317-318.

51. Parry BL, Meliska CJ, Martinez LF, et al. Menopause: Neuroendocrine changes and hormone replacement therapy. J Am Med Womens Assoc. 2004;59(2):135-145.

52. Prange AJ, Wilson IC, Alltop LB. Estrogen may well affect response to antidepressant. JAMA. 1972;219:143-144.

53. Schneider LS, Small GW, Hamilton SH, Bystritsky A, Nemeroff CB, Meyers BS. Estrogen replacement and response to fluoxetine in a multicenter geriatric depression trial. Fluoxetine Collaborative Study Group. Am J Geriatr Psychiatry. 1997;5(2):97-106.

54. Liu P, He FF, Bai WP, et al. Menopausal depression: Comparison of hormone replacement therapy and hormone replacement therapy plus fluoxetine. Chin Med J (Engl). 2004;117(2):189-194.

55. Schneider LS, Small GW, Clary CM. Estrogen replacement therapy and antidepressant response to sertraline in older depressed women. Am J Geriatr Psychiatry. 2001;9(4):393-399.

56. Tam LW, Parry BL. Does estrogen enhance the antidepressant effects of fluoxetine? J Affect Disord. 2003;77(1):87-92.

57. Amsterdam J, Garcia-Espana F, Fawcett J, et al. Fluoxetine efficacy in menopausal women with and without estrogen replacement. J Affect Disord. 1999;55(1):11-17.

58. Rasgon NL, Dunkin J, Fairbanks L, et al. Estrogen and response to sertraline in postmenopausal women with major depressive disorder: A pilot study. J Psychiatr Res. 2007;41(3-4):338-343.

59. Freeman MP, Hill R, Brumbach BH. Escitalopram for perimenopausal depression: An open-label pilot study. J Womens Health (Larchmt). 2006;15(7):857-861

60. Soares CN, Arsenio H, Joffe H, et al. Escitalopram versus ethinyl estradiol and norethindrone acetate for symptomatic peri- and postmenopausal women: Impact on depression, vasomotor symptoms, sleep, and quality of life. Menopause. 2006;13(5):780-786.

61. Soares CN, Poitras JR, Prouty J, Alexander AB, Shifren JL, Cohen LS. Efficacy of citalopram as a monotherapy or as an adjunctive treatment to estrogen therapy for perimenopausal and postmenopausal women with depression and vasomotor symptoms. J Clin Psychiatry. 2003;64(4):473-479.

62. Stahl SM. Basic psychopharmacology of antidepressants, Part 2: Estrogen as an adjunct to antidepressant treatment. J Clin Psychiatry. 1998;59 Suppl 4:15-24.

63. Rasgon NL, Altshuler LL, Fairbanks LA, et al. Estrogen replacement therapy in the treatment of major depressive disorder in perimenopausal women. J Clin Psychiatry. 2002;63 Supp1 7:45-48.

64. Shapira B, Oppenheim G, Zohar J, Segal M, Malach D, Belmaker RH. Lack of efficacy of estrogen supplementation to imipramine in resistant female depressives. Biol Psychiatry. 1985;20(5):576-579.

65. Zohar J, Shapira B, Oppenheim G, Ayd FJ, Belmaker RH. Addition of estrogen to imipramine in female-resistant depressives. Psychopharmacol Bull. 1985;21(3):705-706.

66. Oppenheim G. A case of rapid mood cycling with estrogen: Implications for therapy. J Clin Psychiatry. 1984;45(1):34-35.

67. Chouinard G, Steinberg S, Steiner W. Estrogen-progesterone combination: Another mood stabilizer? Am J Psychiatry. 1987;144(6):826. 
68. Sloan DM, Kornstein SG. Gender differences in depression and response to antidepressant treatment. Psychiatr Clin North Am. 2003;26(3): 581-594.

69. Joffe H, Groninger H, Soares CN, Nonacs R, Cohen LS. An open trial of mirtazapine in menopausal women with depression unresponsive to estrogen replacement therapy. J Womens Health Gend Based Med. 2001;10(10):999-1004.

70. Ladd CO, Newport DJ, Ragan KA, Loughhead A, Stowe ZN. Venlafaxine in the treatment of depressive and vasomotor symptoms in women with perimenopausal depression. Depress Anxiety. 2005;22(2): 94-97.

71. Dias RS, Kerr-Correa F, Moreno RA, et al. Efficacy of hormone therapy with and without methyltestosterone augmentation of venlafaxine in the treatment of postmenopausal depression: A double-blind controlled pilot study. Menopause. 2006;13(2):202-211.

72. Joffe H, Soares CN, Petrillo LF, et al. Treatment of depression and menopause-related symptoms with the serotonin-norepinephrine reuptake inhibitor duloxetine. J Clin Psychiatry. 2007;68(6):943-950.

73. Klaiber EL, Broverman DM, Vogel W, Kobayashi Y. Estrogen therapy for severe persistent depressions in women. Arch Gen Psychiatry. 1979;36(5):550-554.

74. Cagnacci A, Volpe A, Arangino S, et al. Depression and anxiety in climacteric women: Role of hormone replacement therapy. Menopause. 1997;4(4):206-211.

75. Schmidt PJ, Nieman L, Danaceau MA, et al. Estrogen replacement in perimenopause-related depression: A preliminary report. Am J Obstet Gynecol. 2000;183(2):414-420.

76. Soares CN, Almeida OP, Joffe H, Cohen LS. Efficacy of estradiol for the treatment of depressive disorders in perimenopausal women: A double-blind, randomized, placebo-controlled trial. Arch Gen Psychiatry. 2001;58(6):529-534.

77. Cohen LS, Soares CN, Poitras JR, Prouty J, Alexander AB, Shifren JL. Short-term use of estradiol for depression in perimenopausal and postmenopausal women: A preliminary report. Am J Psychiatry. 2003;160(8):1519-1522.

78. Carranza-Lira S, Valentino-Figueroa ML. Estrogen therapy for depression in postmenopausal women. Int J Gynaecol Obstet. 1999;65(1): 35-38.

79. Morrison MF, Kallan MJ, Ten Have T, Katz I, Tweedy K, Battistini M Lack of efficacy of estradiol for depression in postmenopausal women: A randomized, controlled trial. Biol Psychiatry. 2004;55(4):406-412.
80. Palinkas LA, Barrett-Connor E. Estrogen use and depressive symptoms in postmenopausal women. Obstet Gynecol. 1992;80(1):30-36.

81. Soares CN, Joffe H, Cohen LS, Almeida OP. Efficacy of 17 beta-estradiol on depression: Is estrogen deficiency really necessary? J Clin Psychiatry. 2002;63(5):451; author reply 451-452.

82. Hays J, Ockene JK, Brunner RL, et al. Effects of estrogen plus progestin on health-related quality of life. $N$ Engl J Med. 2003;348(19): 1839-1854.

83. Hlatky MA, Boothroyd D, Vittinghoff E, Sharp P, Whooley MA. Quality-of-life and depressive symptoms in postmenopausal women after receiving hormone therapy: Results from the Heart and Estrogen/ Progestin Replacement Study (HERS) trial. JAMA. 2002;287(5): 591-597.

84. Sherwin BB. The impact of different doses of estrogen and progestin on mood and sexual behavior in postmenopausal women. J Clin Endocrinol Metab. 1991;72(2):336-343.

85. Dennerstein L, Burrows GD, Hyman GJ, Sharpe K. Hormone therapy and affect. Maturitas. 1979;1(4):247-259.

86. Pinkerton JV, Pastore LM. Perspective on menopausal vasomotor symptoms, CAM, and the SWAN. Menopause. 2007;14(4):601-605.

87. Carroll DG, Kelley KW. Use of antidepressants for management of hot flashes. Pharmacotherapy. 2009;29(11):1357-1374.

88. Lekander I, Borgstrom F, Strom O, Zethraeus N, Kanis JA. Cost-effectiveness of hormone therapy in the United States. J Womens Health (Larchmt). 2009;18(10):1669-1677.

89. Rossouw JE, Anderson GL, Prentice RL, et al. Risks and benefits of estrogen plus progestin in healthy postmenopausal women: Principal results from the Women's Health Initiative randomized controlled trial. JAMA. 2002;288(3):321-333.

90. Turgeon JL, McDonnell DP, Martin KA, Wise PM. Hormone therapy: Physiological complexity belies therapeutic simplicity. Science. 2004;304(5675):1269-1273.

91. Rossouw JE, Prentice RL, Manson JE, et al. Postmenopausal hormone therapy and risk of cardiovascular disease by age and years since menopause. JAMA. 2007;297(13):1465-1477.

92. Ettinger B, Barrett-Connor E, Hoq LA, Vader JP, Dubois RW. When is it appropriate to prescribe postmenopausal hormone therapy? Menopause. 2006;13(3):404-410.

93. Geller SE, Studee L. Botanical and dietary supplements for mood and anxiety in menopausal women. Menopause. 2007;14(3 Pt 1): $541-549$.
International Journal of Women's Health

\section{Publish your work in this journal}

The International Journal of Women's Health is an international, peerreviewed open-access journal publishing original research, reports, reviews and commentaries on all aspects of women's healthcare including gynecology, obstetrics, and breast cancer. Subject areas include: Chronic conditions (migraine headaches, arthritis, osteoporosis);

\section{Dovepress}

Endocrine and autoimmune syndromes; Sexual and reproductive health; Psychological and psychosocial conditions. The manuscript management system is completely online and includes a very quick and fair peer-review system. Visit http://www.dovepress.com/ testimonials.php to read real quotes from published authors. 